José Roberto de Souza Freire ${ }^{1}$

Izabel Cristina dos Santos ${ }^{2}$

Fernando Paim Costa ${ }^{3}$

\title{
Competências inovativas e a acumulação do conhecimento: um estudo de caso em uma inovação tecnológica da pecuária de corte.
}

\section{Resumo}

Este artigo tem como objetivo descrever o processo de gerar competências inovadoras na Empresa Brasileira de Pesquisa Agropecuária. No inicio de 1980, o centro de pesquisa da Embrapa Gado de Corte estava engajado no projeto Marandu - Brachiaria brizantha originalmente uma planta nativa da África, potencialmente usada para alimentação do gado. Atualmente é responsável por cerca de $40 \%$ das sementes de forrageiras vendidas no Brasil, cultivada em cerca de 70 milhões de hectares de pastagens no país. Uma abordagem qualitativa foi definida para a pesquisa exploratória, e delineamento de estudo de caso. Foram feitas entrevistas semiestruturadas com os pesquisadores envolvidos no projeto e examinado os processos de geração, armazenamento, distribuição e aplicação do modelo de conhecimento tecnológico aplicado pela Embrapa. Os resultados obtidos evidenciam a relevância do ciclo de geração de competências nos processos da gestão do conhecimento, essenciais nas tecnologias da pecuária de corte do agronegócio.

Palavras-chave: Gestão do conhecimento; Competência inovativa; Pesquisa e Desenvolvimento; Agronegócio.

\section{Innovative skills and accumulation of knowledge: a case study in a technological innovation of beef cattle.}

\begin{abstract}
This article aims to describe the process of generating innovative skills at Brazilian Organization for Agricultural Research - EMBRAPA. At the beginning of 1980, EMBRAPA Beef Cattle Research Center was engaged in the Marandu project, working with Brachiaria brizantha, a native grass originated from Africa, potentially used to feed livestock. Such species is currently responsible for about $40 \%$ of forage seeds sold in Brazil, and is grown as pasture on about 70 million hectares in the country. The description, an exploratory research, was based on a qualitative approach, designed as a case study. Semi-structured interviews were conducted with researchers involved in the project, in order to describe the processes of generation, storage, distribution and application of the technological knowledge model applied by EMBRAPA. Results show the relevance of the skills generation cycle in the processes of knowledge management, essential for developing new technologies for the beef cattle sector.
\end{abstract}

Keyword: Knowledge Management; Innovative Competences; Research and Development; Agribusiness.

(1) Pesquisador Analista A da Empresa Brasileira de Pesquisa Agropecuária e Professor da Universidade Estácio de Sá, Campo Grande, Mato Grosso do Sul. (joserobertofreire@gmail.com)

(2) Izabel Cristina dos Santos, Professora da Universidade Municipal de São Caetano do Sul em São Paulo e do Pesquisador A da EMBRAPA. (isa.santos.sjc@gmail.com)

(3) Fernando Paim Costa, Pesquisador A da Empresa Brasileira de Pesquisa Agropecuária, EMBRAPA. (fernando-paim.costa@embrapa.br) 


\section{Introdução}

O padrão tecnológico atual da agropecuária deve ser compreendido como resultado do esforço de diversos agentes - empreendedores e produtores rurais, universidades, centros de pesquisa, indústria, pesquisadores e órgãos de fomento - articulados no intuito de modernizar o setor agrícola e buscar a independência tecnológica.

Contudo, para garantir essa autonomia tecnológica, é importante manter um ritmo contínuo de aprendizagem e buscar o conhecimento nas fronteiras do saber tecnológico. Para tanto, as interações entre os diversos agentes devem ser tomadas pelo seu valor estratégico e, gradativamente ampliadas, visando construir as redes institucionais de relacionamento, do local para o global, pois a demanda por alimentos é mundial e perene.

No campo das Ciências Naturais, Engenharias e, mais recentemente, nas Ciências da Terra, as fronteiras do conhecimento são continuamente desafiadas à produção de novas soluções tecnológicas, o que induz o aumento progressivo na densidade do conhecimento científico e na qualificação dos quadros de pesquisadores.

A busca pelo aumento da capacidade de atendimento de demandas globais por produtos e serviços tem reconfigurado a função da Pesquisa, Desenvolvimento e Inovação - PD\&I - como meio de fortalecimento das competências tecnológicas nacionais. Dessa forma, o domínio de fronteiras tecnológicas conflui para a competitividade nacional da indústria, uma vez que o conhecimento gerado nos centros de pesquisa é transferido para o setor produtivo, o que, ao longo do tempo, promove uma espiral do desenvolvimento, com geração de riquezas e de poder. Assim, o desenvolvimento de campos específicos do conhecimento contribui para o desenvolvimento de um país.

No Brasil, observa-se um forte avanço da participação do setor privado em segmentos específicos da PD\&I, embora ainda se destaque a participação do setor público em segmentos estratégicos, mediante programas de fomento promovidos pelos fundos setoriais. Uma dimensão deste avanço pode ser verificada ao se comparar a participação do capital público e privado nos investimentos em pesquisa a partir da década de 1990. As empresas brasileiras (sede ou subsidiárias), em média, ampliaram seus investimentos em pesquisa e desenvolvimento de 20\% do volume total, para 43,9\%, em 2008 (Fonseca, 2001; Brasil, 2012). Em relação aos países com sistemas de inovação maduros, os investimentos em PD\&l feitos no Brasil atingiram os volumes apresentados na Tabela 1:

Tabela 1- Investimentos em PD\&I nos países com domínio das fronteiras tecnológicas

\begin{tabular}{|c|c|c|c|c|c|}
\hline $\begin{array}{l}\text { País com Sistema } \\
\text { de Inovação }\end{array}$ & & & & 2008 & \\
\hline & Governo ${ }^{\text {*1 }}$ & Empresas & Governo & Empresas & Outros \\
\hline Alemanha & $11,00 \%$ & $89,00 \%$ & $27,70 \%$ & $67,90 \%$ & $4,40 \%$ \\
\hline Estados Unidos & $14,00 \%$ & $86,00 \%$ & $27,00 \%$ & $67,30 \%$ & $5,70 \%$ \\
\hline França & $27,00 \%$ & $73,00 \%$ & $39,40 \%$ & $50,50 \%$ & $10,10 \%$ \\
\hline Itália & $30,00 \%$ & $70,00 \%$ & $44,30 \%$ & $42,00 \%$ & $13,70 \%$ \\
\hline Japão & $11,00 \%$ & $89,00 \% \%^{\mathrm{N} 2}$ & $15,60 \%$ & $77,70 \%$ & $6,70 \%$ \\
\hline Reino Unido & $23,00 \%$ & $77,00 \%{ }^{\mu_{2}}$ & $29,50 \%$ & $47,20 \%$ & $23,30 \%$ \\
\hline
\end{tabular}

*1: Percentuais obtidos por extrapolação. *2: Dados disponíveis do ano de 1988

Fonte: Fonseca; Sbragia et al; Santos (2001; 2006; 2012) 
Dado o crescimento nos volumes de investimento privado em PD\&l no País, e o decréscimo do investimento privado em países de industrialização antiga, somado à pressão contemporânea pela redução de ciclos de produção em indústrias de base tecnológica (Santos, 2004), é possível inferir sobre um vicejante aumento na geração e na diversidade de artefatos e serviços tecnológicos os quais, afetarão o nexo ciência e inovação tecnológica na abordagem da aprendizagem do processo de acumulação de estoque e na geração de capacidade ao longo tempo.

Do fato descrito resulta o entendimento sobre a importância desta pesquisa, uma vez que desponta no Brasil, com a publicação do Livro Azul de Ciência, Tecnologia e Inovação, em 2010, pelo então Ministério da Ciência e Tecnologia, com diretrizes estratégicas para o desenvolvimento cientifico e tecnológico do país, a perspectiva e, pelo cenário político e econômico mundial, a oportunidade de ingresso gradual do país na arena competitiva, em setores de alta tecnologia, com ampliação da produtividade no setor de agronegócios.

Nesse contexto, para a construção deste trabalho, elaborou-se uma questão central de pesquisa: como se desenvolve a acumulação do conhecimento e gera as competências inovadoras em uma Unidade de Pesquisa Científica? Entender e trabalhar esse processo são pontos importantes, pois muitos gestores e líderes não percebem como a natureza do conhecimento esta pressionando as organizações a promoverem mudanças internas e externas, numa nova ecologia organizacional.

O objetivo deste trabalho é descrever o processo de gerar competência inovadora na Empresa Brasileira de Pesquisa Agropecuária- Embrapa, tendo por referência o caso da adaptação da forrageira conhecida como capim Marandu, desenvolvido pela Embrapa, no Centro de Pesquisa de Gado de Corte, Campo Grande, no estado do Mato Grosso do Sul, Brasil.

\section{Revisão de literatura}

A partir da década de 1960, as revoluções tecnológica, econômica e cultural têm desafiado o sistema de ideias, de técnicas e a institucionalidade dominantes na época histórica do industrialismo, e que modelaram as relações de produção, relações de poder, formas de viver e a cultura desse período histórico desde o século XVIII (Castells, 1996).

Embora, a aprendizagem industrial tenha sido objeto recorrente de estudos no campo da Psicologia do Trabalho desde a década de 1960, o tema ganhou força na década de 1990, a partir da associação do conhecimento como um recurso da organização, com forte impacto na construção de vantagens competitivas sustentáveis.

Da associação entre os conceitos de aprendizagem, recursos e capacidades, novas, e antigas, porém, revisitadas perspectivas têm gerado estudos empíricos sobre a construção do conhecimento e das competências tecnológicas desenvolvidas por empresas, ou mesmo países, de industrialização recente, como o caso da Coreia, apresentado por (Kim, 1997), que evidencia a curva crescimento das capacidades inovativas, a partir da estratégia de imitação.

A difusão de pesquisas sobre as capacidades tecnológicas específicas da empresa, como o caso da Embraer, descrito por (Santos, 2004), apontam os processos de aprendizagem como os principais responsáveis pelo desempenho competitivo nas empresas inovadoras dos países industrializados (Miranda e Figueiredo, 2010).

O entendimento do processo de acumulação tecnológica, principalmente no tocante à empresa que atua na inovação do agronegócio, é de fundamental importância no contexto de economias em desenvolvimento. Para que estas alcancem a fronteira tecnológica, é necessário que acelerem o processo de acumulação tecnológica a uma taxa normalmente mais rápida do que a observada em empresas de economias altamente industrializadas (Bell e Pavitt, 1995; Figueiredo, 2004). 


\subsection{A pesquisa agropecuária brasileira}

Em 40 anos, O Brasil construiu um sistema produtivo reconhecidamente eficiente e competitivo no que se refere à agropecuária. Esse alcance foi estimulado, em grande parte, pela geração de conhecimento e das ações advindas do Sistema Nacional de Pesquisa Agropecuária - SNPA.

Como característica operacional, o SNPA conta com as unidades de pesquisas descentralizadas e organizações estaduais de pesquisa, universidades e outras instituições afins. Essa forma de arranjo possibilitou a incorporação de inovações que garantiram consideráveis saltos na produtividade e na qualidade dos produtos agrícolas, resultando em uma participação muito consistente do setor de agronegócios no processo de desenvolvimento econômico brasileiro, principalmente a partir da década de 1970.

A criação da Empresa Brasileira de Pesquisa Agropecuária (Embrapa) em 1973 foi uma importante iniciativa na promoção do desenvolvimento tecnológico no setor agrícola nacional. A principal função da pesquisa pública na agricultura, expressa na missão da Embrapa, é viabilizar soluções para o desenvolvimento sustentável por meio da geração, adaptação e transferência de conhecimentos e tecnologias ao setor produtivo.

A pesquisa, o desenvolvimento e a inovação (PD\&l) associados à transferência de conhecimentos e tecnologia são os principais pilares para o desenvolvimento de um agronegócio realmente sustentável. Esses sustentáculos têm sido a base para produção de alimentos, fibras e energia renovável no mundo (Soares, 2012).

Especialmente, em razão do debate sobre o ambiente e sustentabilidade, conforme descrito por (Freeman e Soete, 1997), a onda das novas tecnologias ambientais e o crescimento da oferta de conhecimentos e produtos derivados da pesquisa no campo da biotecnologia e da nanotecnologia, tendem a endereçar maiores volumes e consideráveis esforços de pesquisa, internacional, inclusive, no setor de agronegócios, incluindo o surgimento de novas tendências e a progressiva ampliação do uso de produtos ligados a ambos os campos de conhecimento e em particular, à agricultura de precisão e à bioenergia.

A missão da Embrapa exige, para seu cumprimento, a geração de conhecimentos científicos capazes de gerarem produtos e práticas de conteúdo tecnológico inovador. Essa missão impõe à Embrapa a utilização imediata da acumulação de suas competências inovativas e do estoque de aprendizagem/conhecimento.

A gestão do conhecimento, mudança tecnológica e inovação têm sido frequentemente associadas às mudanças econômicas e sociais nos diversos países e o sucesso das empresas depende, cada vez mais, da eficácia com que incorporam os novos conhecimentos nos seus produtos e serviços (Nelson e Winter, 1982; 1997; Nelson e Kim, 2005).

O impacto do conhecimento na inovação tecnológica e seu transbordamento para o mercado foi, primariamente descrita por Joseph Schumpeter, cuja obra enfatiza a importância das inovações e dos avanços tecnológicos no desenvolvimento das empresas e da economia, com seu paradoxo do "desequilíbrio dinâmico" como o único estado estável da economia, e a "destruição criativa", por parte dos inovadores, como a força impulsora da economia (Schumpeter, 1970).

Responder aos desafios e aproveitar as oportunidades propiciadas pela estrutura e pelas equipes de PD\&I é o segredo para manter a trajetória de sucesso e o avanço na modernização do modelo de gestão, do que depende a atuação em uma perspectiva duradoura, criando competências tecnológicas inovativas e promovendo a inovação organizacional e a capacitação gerencial (Embrapa, 2008).

A solução de um problema de natureza "aplicada" pode exigir desenvolvimento científico de natureza teórica e metodologia. Quando isso ocorre, os pesquisadores da empresa, 
por si mesmos ou em articulação em rede com seus colegas e parceiros de pesquisa, precisam garantir a execução desses estudos básicos, como pré-requisito para o sucesso no desenvolvimento dos projetos de pesquisa.

O trabalho experimental, que se fundamenta na acumulação da aprendizagem e nas competências inovadoras envolve equipes multidisciplinares, que atuam nas fronteiras do saber das suas áreas de atuação, contribuem com o conhecimento específico para a geração de um novo produto como, por exemplo, uma "cultivar forrageira". Nesse caso, o trabalho envolve várias áreas do conhecimento, com especialistas em entomologia, fitopatologia, fertilidade dos solos, citogenética, biotecnologia, fisiologia vegetal, nutrição animal, impacto ambiental, avaliação de pastagens, produção de sementes, gestão do conhecimento e transferência da tecnologia.

\subsection{Geração do Conhecimento e o Desconhecimento}

Lima (2005, p. 110) aborda sobre as decorrências da incorporação do conhecimento ao sistema alimentar. No entanto, o avanço do conhecimento exige a incorporação da informação a esses sistemas de geração e inovação de tecnologias, afirmando que a base para tais mudanças é um novo paradigma tecnológico, representado pela informática e pela biotecnologia, também pelos desenvolvimentos na nanotecnologia e que muitas vezes não são absorvidas pelo consumidor.

Em relação à biotecnologia, Lopes (1998 p.114), destaca que em países em desenvolvimento a biotecnologia pode ter mais impactos positivos, ao produzir alimentos mais nutritivos, ao permitir a adaptação das culturas a ambientes limitantes, como os encontrados nos trópicos, e ao reduzir a necessidade de aplicação de insumos caros ou indesejáveis do ponto de vista ambiental.

Morin (1996, p.27) comenta as condições socioculturais do conhecimento "é necessário igualmente enraizar o conhecimento científico nas suas condições socioculturais de formação". O autor evidencia que ao longo do século XIX, foi necessário criar um conceito da energia a ideia do trabalho, porque ninguém vê a energia no seu estado puro e sim sob suas diferentes manifestações, o qual pode perceber sobre o conceito do conhecimento e inovação competitiva.

Esses novos desafios pautados por uma nova forma de fazer ciência são derivados de inúmeras tecnologias/corpo de conhecimento, pelo seu potencial de aplicação a diversas áreas de atividade humana e, enfim, pela mudança que como consequência, causa na vida cotidiana das pessoas, ou seja, gerador, produtor ou consumidor, criando novas concepções de fazer na inovação da agropecuária.

Torna-se, portanto, necessária à definição de conceitos como 'conhecimento organizacional' e 'aprendizagem organizacional', para que se possa estudar a formação e desenvolvimento de competências e a sua relação com o projeto organizacional.

\subsection{Aprendizagem e conhecimento organizacional}

De acordo com Fernandes (1999), na compreensão da aprendizagem organizacional deve-se explorar a forma pela qual as empresas constroem, incrementam e organizam conhecimento e rotinas, e as suas relações com resultados e processos que ocorrem no interior das organizações. Tal estudo deve incorporar o seguinte conjunto de premissas:

- A aprendizagem geralmente tem consequências positivas, mesmo quando os resultados são negativos, o produto deste processo está na compreensão das relações de causa-efeito; 
- Mesmo que o aprendizado centre-se no indivíduo, as empresas também aprendem, pode-se estabelecer uma representação social ao processo de aprendizagem organizacional;

- A aprendizagem ocorre através de todas as atividades da empresa, em diferentes processos e em diferentes níveis.

No campo da psicologia organizacional e do trabalho, aprendizagem individual é uma mudança comportamental, relativamente permanente, associada à experiência, que envolve os planos afetivo, cognitivo e motor, garantindo capacidade transformadora do ser humano. Essa definição de aprendizagem individual filia-se às correntes cognitivistas, segundo as quais mudanças em comportamentos e atitudes ocorrem não só por meio de interações do indivíduo com o ambiente, mas também pela mediação de processos cognitivos internos (Abbad e Borges-Andrade, 2008).

Aprendizagem é o resultado da transferência do conhecimento em ação, é um processo de busca e apreensão, dependendo do sentido da busca e da expectativa do ser humano por meio da observação, da sensação e da expectativa e conduzem a vivenciar novas experiências e a compartilhar essa experiência com alguém ou em grupo.

Para converter essa aprendizagem individual em aprendizagem organizacional é necessário que a organização empresarial crie desejo comum como um desafio a ser superado proporcionado um sentido de direção, cria-se a partir desta situação, uma linguagem figurativa e de simbolismo do orgulho de pertencer à organização, podendo ser o desenvolvimento de um projeto de um produto ou serviço e em grupo interprete novos eventos e situações a serem resolvidas. Não que seja um ato isolado de indivíduo e sim de grupo/equipe. Além disso, é preciso considerar que boa parte do conhecimento compartilhado em uma organização é tácito, fato que confere especial valor à transmissão de saber e aprendizagens socioculturais (Takeuchi e Nonaka, 2008).

Neste contexto, é importante destacar a necessidade de compartilhar insights, crenças e metas para que o coletivo prevaleça e a organização construa e aprenda. Nesse momento, a aprendizagem individual é transformada em coletiva e o conhecimento individual é incorporado às práticas organizacionais.

Esse é um conceito que vem sendo desenvolvido a muitos anos de acordo com Fleury e Fleury (2006) e requer a conscientização de que não existe fim, pois a ação e a reação advindas das mudanças externas ou internas, ocorridas no ambiente ou no indivíduo, fazem parte do processo de aprendizagem.

Takeuchi e Nonaka (2008, p.60) postularam quatro modos diferentes de conversão do conhecimento: socialização, externalização, combinação, internalização.

- Socialização - (tácito para tácito): é o lugar onde o processo de criação inicia. É um processo de compartilhamento de experiências, observação, imitação e prática. As experiências face-a-face são a chave para a transferência do conhecimento tácito.

- Externalização - (tácito para explícito): é mais conscientemente construída. Modelos mentais individuais, expressos na forma de metáforas, analogias, conceitos, hipóteses ou modelos. O modo de externalização do conhecimento é visto geralmente no processo de criação do conceito e é provocado pelo diálogo ou pela reflexão coletiva.

A metáfora, por exemplo, é uma forma de perceber ou entender intuitivamente uma coisa imaginando outra simbolicamente. É também uma ferramenta importante para a criação de uma rede de novos conceitos. Esse processo criativo e cognitivo continua à medida que pensamos nas semelhanças entre os conceitos e sentimos um desequilíbrio, contradição ou incoerência em suas associações, o que leva à descoberta de um novo significado ou à formação de um novo paradigma. 
- Combinação - (explícito para explícito): é o processo de sistematização de conceitos existentes em um novo sistema de conhecimentos. A combinação de um novo conhecimento explícito com uma informação e conhecimentos pré-existentes gera e sistematiza o conhecimento explícito por toda a organização. A reconfiguração das informações existentes através da classificação, do acréscimo, da combinação e da categorização do conhecimento explícito pode levar a novos conhecimentos.

- Internalização - (explícito para tácito): consiste basicamente no exercício continuado que enfatiza e treina certos modelos/padrões. Focaliza o treino com mestres experientes e colegas. Em vez de ensinar baseado em análise, ensina pelo contínuo processo de autoaprimoramento, onde a ativa participação é enfatizada. Quando são internalizadas nas bases do conhecimento tácito dos indivíduos sob a forma de modelos mentais ou know-how técnico compartilhado, as experiências através da socialização, externalização e combinação tornam-se ativos valiosos.

O conhecimento tácito tem um papel fundamental para explicar porque a compreensão de temas complexos pode ser prejudicada, quando se busca faze-lo, primordialmente, a partir de sua decomposição em partes e análise estritamente racionais. Apesar do esforço teórico em explicar e formular modelos de gestão de conhecimento é imprescindível destacar que o conhecimento está baseado na efetividade em que se apoie as estratégias do negócio e assimila a adoção da inovação nos serviços e produtos.

Figueiredo (2004) examina os processos de aprendizagem na acumulação de competência numa empresa de bens de capital na busca da gestão do desenvolvimento e define competência tecnológica como os recursos necessários para gerir mudanças tecnológicas, entendida como as habilidades da empresa para realizar atividades inovadoras em produtos e processos.

A capacidade cumulativa do aprendizado produtivo reforça o caráter tácito e específico do conhecimento, o que permite aos empreendedores/produtores rurais obterem vantagens competitivas. A inovação tecnológica visa à ampliação da capacidade de produção da terra e do trabalho, sendo a sua dinâmica propulsora de oportunidades tecnológicas.

A capacidade gerencial do agricultor é fundamental no processo de exploração das vantagens competitivas e dos ganhos produtivos do conhecimento tecnológico. O processo de aprendizado (via experimentação) está associado à absorção do novo conhecimento, não somente à adequação de elementos tácitos no emprego deste conhecimento ou da tecnologia na unidade produtiva.

A constituição da trajetória tecnológica é moldada pela interação entre a pesquisa básica e a aplicada, sendo mais intensa, num primeiro momento, nos conhecimentos fundamentais e, posteriormente, nas soluções dos problemas de natureza técnica.

A experiência e o aprendizado do produtor no uso da nova tecnologia não apenas reduzem o risco ligado ao fator exógeno (adversidades climáticas, variabilidade geográfica e surgimento de novas pragas e doenças) como também redirecionam as trajetórias mais amplas do segmento fornecedor. Esta situação é ocasionada devido ao efeito de feedback que adapta e melhora a tecnologia à diversidade ambiental e às necessidades dos produtores.

\section{Metodologia}

O presente estudo tem uma natureza qualitativa, de caráter exploratório descritivo, buscando apreender uma situação in loco, estabelecendo comparações com outras situações vivenciadas e com um referencial teórico previamente firmado, buscando relacionar os elementos de aprendizagem e competência organizacional à compreensão da realidade.

Foram conduzidas entrevistas semiestruturadas, entrevistas com os pesquisadores 
envolvidos no projeto de pesquisa da forrageira e análise documental. Para um melhor ajuste no instrumento de coleta de dados, foi realizada uma entrevista teste com um dos atores envolvidos na geração da tecnologia.

A questão básica que se propõe ao estudo refere-se a quais processos são utilizados pela Embrapa Gado de Corte para acumulação de aprendizagem e geração de competência inovadora no agronegócio. O foco de estudo é a tecnologia gerada conhecida como capim Marandu, sendo fonte nutritiva para a criação e engorda de animais em pastos cultivados, capaz de promover um diferencial qualitativo e quantitativo para a carne de qualidade.

As forrageiras Marandú, Xaraés, Tanzânia, Mombaça, Massai e Piatã, entre outras gramíneas, correspondem à maioria das pastagens em uso no Brasil e têm alcance internacional, abrangendo as áreas tropicais. A cultivar Marandu, por exemplo, está presente em pelo menos $50 \%$ das pastagens em área de cerrados (Costa e Cardoso, 2009). As sementes dessas forrageiras são, também, fonte de riqueza para o País, pois sua comercialização movimenta cerca de 240 milhões de dólares anuais, equivalente ao do mercado de sementes de milho (Resende et al, 2008).

A coleta de informações e dados para o artigo começa durante a revisão dos conceitos de aprendizagem e competências tecnológicas, tendo em vista a necessidade de se buscar desenvolver o tema, conciliando aspectos teóricos e práticos. Visando tornar o estudo mais condizente com a realidade, foram formuladas quatro questões básicas para orientar entrevistas dos pesquisadores envolvidos diretamente na tecnologia do capim Marandu. A saber:

1. Explique como ocorreram as seguintes etapas:

a. Geração de Conhecimento (novo) / Captura de Conhecimento Existente. (Isto é, como surgiu a ideia sobre essa forrageira ou como chegou até você?)

b. Armazenamento do conhecimento. (documentação física ou eletrônica sobre a pesquisa).

c. Distribuição do Conhecimento/ Processos de transferência. (como foi passado o conhecimento para equipe e produtor).

d. Aplicação do Conhecimento/ Implementação do resultado do conhecimento. (os cultivares implantados são monitorados? Resultados obtidos)

2. Em quantas etapas você dividiria o desenvolvimento do projeto?

3. Quais são os principais desdobramentos desse conhecimento? (outros resultados alcançados ou novas tecnologias ou métodos)

4. Com sua experiência no desenvolvimento dessa tecnologia, quais os conselhos para quem está começando?

\section{Resultados}

O resultado de pesquisa apontou o modelo de gestão do conhecimento aplicado no projeto e passou por quatro fases, tais como: a) aquisição externa do conhecimento no país e fora do país, tais como a experiência australiana; b) aquisição interna do conhecimento, ou seja, desenvolvimento de sequencias metodológicas, permuta e contratação de novos especialistas, trabalho em equipe e treinamento; c) codificação do conhecimento, com formação de banco de dados, normatizações de procedimentos; d) socialização do conhecimento por meio da difusão da tecnologia Marandu, dia de campo, produção de sementes e capacitação do empreendedores rurais, principalmente os sementeiros.

Com as informações obtidas em fontes primárias e secundárias foi possível descrever o 
processo de conhecimento e competência tecnológica da Embrapa Gado de Corte, com relação ao lançamento do Capim Marandu. Tal descrição esta organizada em quatro características principais, como exibe a Tabela 2, com base na formulação teórica da gestão conhecimento de Takeuchi e Nonaka (2008).

\begin{tabular}{|c|c|c|}
\hline Aquisição externa do conhecimento & Registro & Citação \\
\hline $\begin{array}{l}\text { Busca de experiência de conhecimento } \\
\text { de outras variedades de capirn, no país } \\
\text { e fora do país. }\end{array}$ & $\begin{array}{l}\text { Registro em } 1976 \text {, sobre o número } \\
822 \text { IRI - Intemational Research } \\
\text { Institute. }\end{array}$ & $\begin{array}{l}\text { Saladino Gonçalves Nunes et } \\
a l, 1985 \text {. }\end{array}$ \\
\hline $\begin{array}{l}\text { Especialistas: Perzecarski, Gardener, } \\
\text { França, Dantas e Rayman. }\end{array}$ & $\begin{array}{l}\text { Registro em } 1977 \text {, número } \mathrm{GC} \\
12778 \text {. }\end{array}$ & $\begin{array}{l}\text { Saladino Gonçalves Nunes et } \\
\text { al, } 1985 \text {. }\end{array}$ \\
\hline $\begin{array}{l}\text { Interação com outros especialistas e } \\
\text { para deservolvimentos de projetos e } \\
\text { seminánios. Experiência australiana. }\end{array}$ & 1980 a 1984 & $\begin{array}{l}\text { Ives Hervé Savidan et al, } \\
1985 \text {. }\end{array}$ \\
\hline \multicolumn{3}{|l|}{ Aquisição interna do conhecimento } \\
\hline $\begin{array}{l}\text { Especialista: Saladino Nunes, Raul } \\
\text { Valério, Wilson Koller, Araê Boock, } \\
\text { Maria Isabel Penteado, Darci Gomes. }\end{array}$ & $\begin{array}{l}\text { Aprendizagem por busca e } \\
\text { experimentação. }\end{array}$ & $\begin{array}{l}\text { Saladino Gonçalves Nunes et } \\
\text { al, } 1985 \text {. }\end{array}$ \\
\hline $\begin{array}{l}\text { Deservolvimento de sequências } \\
\text { metodológicas. }\end{array}$ & $\begin{array}{l}\text { Cacilda do Valle, Isabel } 0 . \\
\text { Penteado et al. }\end{array}$ & Programa de melhoramento. \\
\hline $\begin{array}{l}\text { Deservolvimento de projetos e } \\
\text { Treinamentos de equipes. }\end{array}$ & $\begin{array}{l}\text { Saladino Gonçalves Nunes, Isabel } \\
\text { de O. Penteado e Liana Jank. }\end{array}$ & $\begin{array}{l}\text { Ives Hervé Savidan et al, } \\
1985 \text {. }\end{array}$ \\
\hline $\begin{array}{l}\text { Perrmuta de especialistas entre uridade } \\
\text { e troca de informaça. }\end{array}$ & Ives Hervé Savidan et al, 1985. & $\begin{array}{l}\text { Ives Hervé Savidan et al, } \\
1985 \text {. }\end{array}$ \\
\hline Contratação de novos especialistas. & $\begin{array}{l}\text { Departamento de Recursos } \\
\text { Humanos. }\end{array}$ & $\begin{array}{l}\text { Rosangela M. S. Resende et } \\
a l, 2008 \text {. }\end{array}$ \\
\hline \multicolumn{3}{|l|}{ Codificação do conhecimento } \\
\hline Instruções técricas sobre os produtos. & $\begin{array}{l}\text { ORSTOM da França e Centro } \\
\text { Internacional de Agricultura } \\
\text { Tropical -CIAT da Colômbia. }\end{array}$ & $\begin{array}{l}\text { Ives Hervé Savidan et al, } \\
1985 \text {. }\end{array}$ \\
\hline $\begin{array}{l}\begin{array}{l}\text { Elaboração de } \\
\text { procedimentos, }\end{array} \\
\text { codificações. }\end{array}$ & $\begin{array}{l}\text { Departamento do Programa de } \\
\text { Pesquisa - DPP. }\end{array}$ & Errbrapa SEDE, 2000. \\
\hline Formação de banco de dados. & $\begin{array}{l}\text { Ano de } 1977 \text { e } 1978 \text { - Banco Ativo } \\
\text { de Germoplasma - BAG. }\end{array}$ & $\begin{array}{l}\text { Centro Nacional de Recursos } \\
\text { Genéticos, } 1979 .\end{array}$ \\
\hline \multicolumn{3}{|l|}{ Socialização do conhecimento } \\
\hline Lançamento da tecnologia Marandu. & $\begin{array}{l}\text { Registro Marandu (significa } \\
\text { novidade no idioma Guarani) } 1983 .\end{array}$ & $\begin{array}{l}\text { Embrapa Gado de Corte, } \\
1984 .\end{array}$ \\
\hline Registros Agronômicos. & IRI- $822 / 1976 ; 127778$ e $142 / 80$. & $\begin{array}{l}\text { Saladino Gonçalves Nunes et } \\
\text { al, } 1985 \text {. }\end{array}$ \\
\hline Produção de sementes. & Parcerias & www.unipasto.combr \\
\hline Transferência de Tecnologia. & Area de Negócios Tecnológicos. & $\begin{array}{l}\text { Errbrapa - Área de } \\
\text { Transferência de Tecnologia. }\end{array}$ \\
\hline
\end{tabular}

Fonte: elaborado pelos autores

Dentro desses parâmetros de aquisição externa e interna, codificação e socialização que gera e aplica o conhecimento da empresa, toma a forma de soluções tecnológicas do agronegócio. Sendo que esses processos de competências tecnológicas da Embrapa Gado de Corte são realizados dentro de uma rede de cooperação técnica científica com outras Unidades de Pesquisa da Embrapa e Universidades, para avaliação e adaptabilidades e persistência das condições de melhorias nutricionais das plantas forrageiras. 
O resultado da inovação, sob o aspecto da aprendizagem da aquisição e conversão do conhecimento, o conhecimento produzido é armazenado e compartilhado com as outras áreas (núcleo de pesquisa), um novo produto ou serviço, por sua vez mudam as formas de agir e pensar de um projeto de pesquisa individual, passa para um projeto de pesquisa em equipes, em diferentes contextos e momentos e ao longo dos anos na troca de relações e compartilhamento das experiências tácito ao explicito e ao tácito entre os indivíduos numa expectativa coletiva.

Aspectos a serem considerados no projeto, referem-se às três etapas principais (Savidan et al., 1985), a primeira fase a de introdução e avaliação agronômica das plantas forrageiras. A segunda, avaliação sob pressão animal (principalmente resistência ao pisoteio). Finalmente a terceira fase zootécnica onde se avalia o ganho de peso animal.

O uso dessas etapas permitiu a geração da tecnologia ao longo do tempo o que representou com sucesso o lançamento da B.brizantha cv. Marandu em 1984 (Nunes et al., 1984), resistente as pragas das pastagens, constituindo um novo multicultivo a partir das décadas de 1980 até hoje. Essa cultivar Marandu foi lançada no mercado em 1984 e hoje responde por mais de $40 \%$ das sementes de forrageiras comercializadas no Brasil, ocupando cerca de 70 milhões de hectares de pastagens (Soares, 2012). Isso requereu o desenvolvimento de métodos e técnicas para a aquisição e conversão do conhecimento, bem como sua socialização, pode-se observar nas entrevistas juntos aos principais atores pesquisadores que continuam trabalhando no Centro de Pesquisa.

\subsection{Resultados das entrevistas}

Abaixo são transcritas as afirmações colhidas em entrevistas realizadas com três pesquisadores da Embrapa Gado de Corte, diretamente envolvidos nos trabalhos que culminaram com o lançamento da tecnologia do capim Marandu:

\subsection{Pesquisador 1}

"A aprendizagem é socializada principalmente por publicações escrita por meio de folders, comunicado técnico, artigos científicos, palestras e dia de campo com estudantes, sementeiros e produtores rurais. A oportunidade surge na busca de novas alternativas de forrageiras resistentes a seca e frio com maior produção de forragem e sementes e valor nutritivo e o especialista deve sempre estar atento ao que está ocorrendo no mundo e na natureza para verificar nova variabilidade. A avaliação do impacto da tecnologia está principalmente na percepção da comercialização dos produtores de sementes e é calculada a extensão das áreas plantadas.

A implementação do resultado da aprendizagem no manejo de pastagem e produção de sementes depende um pouco de experiência do produtor e o seu nível cultural e a capacitação dos recursos humanos é muito importante desde o plantio com condução acurada de medição das fileiras das parcelas plantadas a observação do crescimento da planta, produção e se há infestação de pragas, bem como o sistema de pastejo consumo da vacaria, engorda e a durabilidade ou resistência do pisoteio animal.

Destaque do entrevistado "a mídia é fator preponderante na transferência do conhecimento e a TV é a forma mais rápida. A principal transferência da tecnologia se dá pela confiança que o produtor tem da Embrapa e pela informação que passa para seu vizinho produtor, assim que dissemina o conhecimento. Às vezes ocorre é que dão apelido para a tecnologia, no caso do Marandu alguns conhecem como Brachiarão". 


\subsection{Pesquisador 2}

"Bem, o nome Marandu foi recebido por ocasião do lançamento, antes existe com o nome e número de um registro, essa cultivar tem apresentado um bom nível de fertilidade, boa produção de pastagem e aceitação dos produtores de sementes e engorda dos bovinos. O projeto se desenvolve primeiramente com a introdução da cultivar na Unidade e são separadas por parcelas dentro da casa de vegetação onde são realizadas vários ensaios de avaliações agronômicas; tipos de solos, adubagens, temperaturas, resistências a calor, frio a pragas de cigarrinhas e outros. Após esses ensaios são levadas a campo para testes nas mesmas condições de ensaios e depois coletados, pesados e separados em folhagens e talos verdes e secos e submetidos a avaliação de laboratório para análise de produção, digestabilidade, qualidade e percentual de proteínas. Em campo verifica a produção de pastagens e resistência à praga e como o animal vai se comportar na alimentação dessa cultivar e uma nova avaliação é realizada com animal e sem animal, sem animal faz uma coleta da planta em 45 dias. Destaca a importância de um equipe de trabalho contínua e permanente para observação e avaliação feedback no comportamento da planta e dos animais em pastagens. As novas competências que têm surgidas nessa área são com o novo conhecimento na área de biologia molecular, surgindo novos modos de reprodução de plantio e serem vivos. Com sua experiência um conselho para quem esta começando é conhecer a forrageira e o solo a ser plantado, acompanhando sempre o comportamento do animal a pasto, o sucesso dependem do olho".

\subsection{Pesquisador 3}

"A ideia surgiu pela demanda de uma espécie mais resistente de leguminosas forrageiras porque as existentes não tinham as qualidades necessárias ao nosso solo, o gado engordava na época de chuva e emagrecia na época seca, surgindo até uma máxima do "efeito sanfona". As sementes vinham da Austrália de navio chegando aqui era jogada de avião ou por correntão o plantio era brutal, sem nenhuma seleção. Isso não teve sucesso, causando fotossensibilização nos animais, aumento das pragas cigarrinhas. Foi nessa época que criaram a Embrapa e ela foi convidada a organizar e orientar, a agonia dos pecuaristas era grande. Se não organizasse essa bagunça não teria a pecuária no Centro Oeste. A Embrapa começou fazendo um levantamento das forrageiras existentes no Brasil e (identificar) quem já estava trabalhando com essas forrageiras, nesse tempo um pecuarista que morava na Nova Campo Grande aqui próximo, apresentou um espécie de Brachiaria que eles achava interessante, nessa época Eu estava fazendo o mestrado nos Estados Unidos, quem começou com tudo isso foi o pesquisador Saladino Nunes, eu fazia parte da equipe em 1981, 82, tinha a Valéria, Inácio. A equipe começou a elaborar uma metodologia de trabalho com a entrada de coleções de capim Panicum que começamos trabalhar com a fase 1, fase 2, fase 3 que realmente resultasse num lançamento de uma cultivar, isso foi aproximadamente de 1980 a 1982 o que sobressai na época era a capim decumbens. Com a chegada do Savidan, vindo da França, nos ajudou bastante a solidificar a metodologia de trabalho, criando um Modus Operandi, trabalhando com canteirinhos passava por ensaios em canteiro maior e depois avaliava em pasto para analisar se o animal ganhava peso ou não. Nós vimos que não adiantava trabalhar apenas com um material o Marandu era um material, começamos a trabalhar com outros materiais como o capim Xaraés, Piatã e começamos a trabalhar com grandes coleções, tendo uma maior potencialidade material que começa a fazer um funil nas etapas de avaliação, que são as fases que já citei. As novas tecnologias - as biotécnicas; marcadores moleculares, técnica de triagem, método de tolerância e resistência as doenças e outras técnicas facilitam uma maior rapidez e confiabilidade nos resultados, proporcionando o conhecimento da divergência genéticas entre os acessos e entre as espécies. Hoje com os avanços de novas variedades de forrageiras temos uma linha de produção com cronograma de lançamentos de novas 
tecnologias, com uma boa parceria de mercado, no caso o setor sementeiro (produtor de sementes), por exemplo, a Unipasto. O tempo de lançamento de novas variedades cultivar é de aproximadamente entre 8 a 10 anos. Precisamos de uma equipe de apoio solidificada e bem treinada o que não esta acontecendo com isso nos demanda tempo para acompanhar os projetos a campo, sempre fala com a equipe de apoio da importância da pesquisa, não podemos fazer de qualquer jeito, por que se colocar lixo no computador sai lixo do outro lado. Nosso processo de transferência hoje é a confiabilidade do nome Embrapa e a divulgação na mídia, folders, boletins, publicações em revistas especializadas, dia de campo, visitas técnicas, o produtor fala para outro produtor. Precisamos de uma cartilha básica e vídeo para ensinar o Modus Operandi do processo produtivo para os pecuaristas. O setor sementeiro é um grande parceiro na divulgação. Na realidade precisamos de transferência, a Embrapa não tem estrutura para fazer transferência de tecnologia no micro, no macro tem. Definitivamente, não temos condições de fazer transferência. Tem que ser terceirizada. Isso: temos que aprender como terceirizar a tecnologia.

A partir da análise dos resultados e do conteúdo dessas entrevistas, com base teórica desenvolvida ao longo do estudo, elaborou-se o processo de geração de competências inovadoras representada na Figura 3 que reúne os elementos que envolvem o processo de pesquisa, com foco no estudo da tecnologia produzida na Embrapa Gado de Corte, a partir do Capim Marandu.

Figura 3. Representação do ciclo da geração de competência inovadora - Capim Marandu.

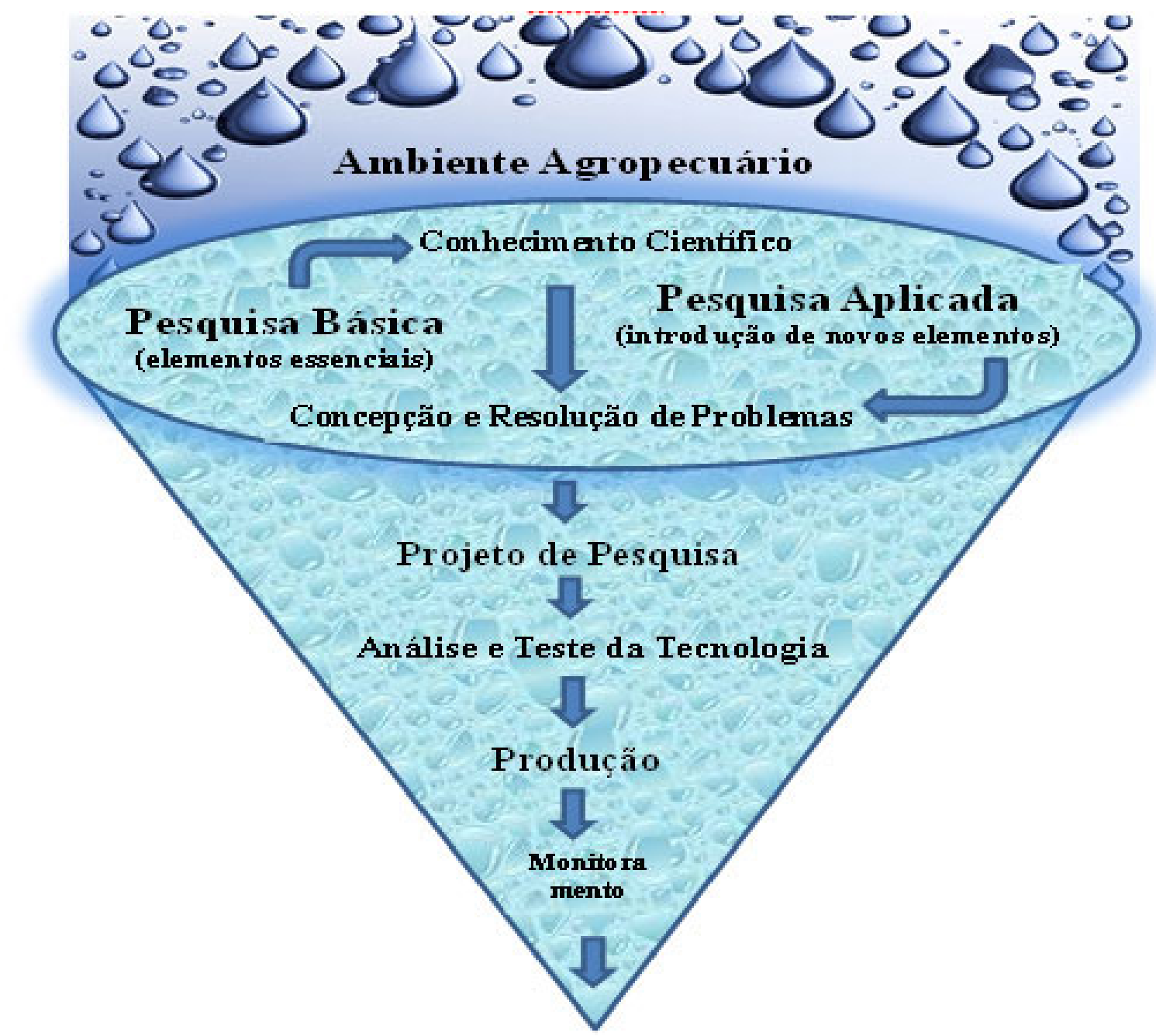

Fonte: Elaborado pelos autores 
O esquema apresentado na figura pressupõe um afunilamento no desenvolvimento da geração da competência inovadora do processo tecnológico do agronegócio de pastagem, desenvolvido após as entrevistas e com apoio nas fundamentações teóricas, principalmente na literatura de melhoramento de forrageiras tropicais (Resende et al., 2008), apresenta as seguintes fases:

1.A introdução de novos elementos: compreende a avaliação agronômica e atende às seguintes etapas: identificação, seleção e análise, avaliadas em pequenos canteiros.

2.A avaliação dos elementos essenciais é a segunda fase, o que envolve a avaliação em piquetes (área em $\mathrm{m}^{2}$ de pastejo), com animais, são analisados características de resistências à praga, ganho de pesos e outros.

3.A terceira fase compreende os testes e avaliação da inovação em ecossistemas distintos.

4.A produção de sementes para lançamento da tecnologia gerada.

A atividade de pesquisa na pecuária de corte é um investimento que demanda, entre 8 a 10 anos de estudos, entre a introdução de novos elementos ao lançamento de novas tecnologias. Mesmo porque, visando a uma recomendação mais abrangente e a diferentes sistemas de produção, a norma de registro de cultivares de forrageiras para pastagens no Ministério da Agricultura, Pecuária e Abastecimento exige ao menos dois locais e dois anos de avaliação sob pastejo, em consequências da complexidade da ciência agrária e do equilíbrio da natureza (Brasil, 2012).

Morin (1996) comenta que a base para tais mudanças é as condições socioculturais do conhecimento para incorporar a nova tecnologia. O terceiro entrevistado relatou acerca das dificuldades da Empresa na difusão da tecnologia. Do seu discurso, destaca-se "A Embrapa não tem estrutura para fazer transferência no micro, no macro tem", ou seja, é preciso de uma política nacional na difusão de tecnologia para garantir a implantação das competências inovadoras geradas.

\section{Conclusão}

Esse artigo abordou a trajetória de competência tecnológica numa empresa pública de pesquisa, desenvolvimento e a inovação (PD\&I), voltada a partir da análise e seleção de forrageiras, especialmente com o capim Marandu, definindo competência tecnológica como a capacidade da instituição de adaptar, desenvolver tecnologia competitiva inovadora. A instituição partiu de um processo de aprendizagem individual na aglutinação da formação de competência por equipe multidisciplinar na contratação e parcerias com outros especialistas.

O processo da geração de competência, conforme constatado nas entrevistas, ocorre desde 1976, com a busca de novas alternativas para atualização do estoque de conhecimento frente ao deslocamento das fronteiras tecnológicas relacionadas à biologia molecular, mais fortemente experimentado em 2008. Para tanto, a Embrapa procedeu à contratação de novos especialistas, com ênfase à busca de novas variedades de cultivar forrageiras. Essa estratégia contribuiu para assegurar um fluxo constante de conhecimento e um melhor entendimento da tecnologia e seus princípios, além de assegurar que o fluxo de novos conhecimentos fosse diligentemente convertido em competência tecnológica acumulada e, consequentemente, na capacidade da Embrapa em oferecer soluções tecnológicas e infraestrutura de pesquisa nos novos objetos de análise. A empresa foi capaz de assegurar suas competências inovadoras em forrageiras tropicais em um processo típico de produção de novas tecnologias.

Novos estudos poderão ser realizados analisando o envolvimento de vários atores na transferência da tecnologia em relação à Gestão Operacional da Pesquisa, uma análise no foco da interdisciplinaridade e, no papel de cada pesquisador.

Outro estudo seria analisar a rede intraorganizacional na busca de informação técnica 
científica de várias áreas do conhecimento, com o objetivo final convergente - competência inovadora - identificando a convergência do conhecimento e da inovação junto ao empreendedor/produtor rural.

É de suma importância a participação da Gestão/Liderança para que exista um mecanismo de retroalimentação para garantir o aperfeiçoamento e o fluxo contínuo de aprendizagem e geração do conhecimento. O conhecimento gerado deve ser incorporado aos sistemas de produção e posto em prática pelos produtores e empreendedores do agronegócio. A competência tecnológica do agronegócio é validada na capacidade gerencial do produtor rural e no processo de exploração das vantagens competitivas das demandas mercadológicas, na forma dos conhecimentos tácitos e explícitos.

\section{REFERÊNCIAS BIBLIOGRÁFICAS}

Abbad, G. da S.; Borges-Andrade, J. E. (2004) Aprendizagem humana em organizações de trabalho. In: Zanelli, José C.; Borges-Andrade, J. E.; Bastos, A. V. B. (Org.). Psicologia, organizações e trabalho no Brasil. Porto Alegre: Artmed. pp. 237-275.

Bell, M; Pavitt, K. The development of technological capabilities: technology and international competitiveness. Washington: The World Bank, 1995.

br/bibliotecadigital., acesso em 3 de julho de 2012.

Brasil. Ministério da Agricultura, pecuária e abastecimento. Politica Agrícola. Disponível em http://www.agricultura.gov.br/politica-agricola. Acesso em 30/07/2012.

Brasil. Ministério da Ciência e Tecnologia. Livro azul: ciência, tecnologia e inovação. Brasília: Ministério da Ciência e Tecnologia, 2010.

Castells, M. The rise of the network society. (1996). Cambridge: Blackwell Publishers. 2004 Vol. N. pp.

Costa, F. P. \& Cardoso E. E. (2009). Relatório de avaliação dos impactos das tecnologias geradas pela Embrapa Gado de Corte. Vol. N. pp.

EMBRAPA. Empresa Brasileira de pesquisa Agropecuária. (2008). Secretaria de Gestão e Estratégia. V Plano-Diretor da Embrapa: 2008-2011-2023. Brasília, DF, Embrapa.

Fernandes, A. C. Conhecimento e Aprendizagem Organizacional em Perspectiva. In: Anais Enegep, 1, 1999, Rio de Janeiro. Disponível http://www.abepro.org.br/biblioteca / ENEGEP1999_A0995.PDF. Acesso em: 18/06/2012.

Figueiredo, P. N. (2004). Aprendizagem tecnológica e inovação industrial em economias emergentes: uma breve contribuição para o desenho e implementação de estudos empíricos e estratégias no Brasil. Revista Brasileira de Inovação, Vol. 3, N. 2, pp. 332-362.

Fleury, A.; Fleury, M.T.L. (2006). Aprendizagem e inovação organizacional: as experiências de Japão, Coréia e Brasil ( $2^{\mathrm{a}}$ ed). São Paulo: Atlas.

Fonseca, R. (1998). Inovação tecnológica e o papel do governo. Parcerias Estratégicas, Brasília: Ministério da Ciência e Tecnologia, Centro de Estudos Estratégicos, n.13, dezembro, 2001. In: Biowork, Viçosa: Aloísio Borém.

Kim, L.; Nelson, R. (orgs.) (2005). Tecnologia, Aprendizado e Inovação. As experiências das economias de industrialização recente. Campinas: Editora da UNICAMP.

Lopes, M.A. (1998). A pesquisa pública frente a um cenário de proteção à propriedade intelectual. In: Borém, A; Del Giúdice M.P; Sakiama, N.S; Moreira, M.A; Portugal, R.S. Biosegurança, proteção de cultivares, acesso a recursos genéticos e propriedade industrial na agropecuária. Viçosa: Universidade Federal de Viçosa. pp.113-118. 
Miranda, Eduardo C; Paulo N. Figueiredo. (2010) Dinâmica daAcumulação de capacidades inovadoras: evidências de empresas de Software no Rio de Janeiro e em São Paulo, ERA • São Paulo • v. $50 \cdot$ n. $1 \cdot$ jan./mar.

Morin, Edgar. (1996). O Problema epistemológico da Complexidade. Portugal: Publicações Europa-América, LTDA.

Nelson, R. R.; Winter, S. G. (1982). An evolutionary theory of economic change. Cambridge: Bellknap Press.

Nunes, S. G.; Boock, A.; Penteado, M. I.; Gomes, D. T. (1984). Brachiaria Brizantha cv. Marandu. Campo Grande, MS: Embrapa-CNPGC. (Documentos, 21).

Resende, M. S. R.; Valle. C. B.; Jank, L. (2008). Melhoramentos de forrageiras tropicais. Campo Grande, MS: Embrapa Gado de Corte.

Santos, I. C. (2004). Um modelo estruturado de gestão do conhecimento em indústrias de base tecnológica: estudo de caso de uma empresa do setor aeronáutico. Tese apresentada ao Programa de Pós- Graduação Politécnica da Universidade de São Paulo.

Santos, I. C. (2102). Notas de Aula. Inovação e Competitividade Organizacional. Programa de Pós-graduação da Universidade Municipal de São Caetano do Sul, São Paulo.

Savidan, Y. H. Jank, L. Penteado, M. I. O. (1985). Introdução, avaliação e melhoramento de plantas forrageiras tropicais no Brasil: novas propostas de Modus Operandi. Campo Grande, Documentos 24. Embrapa.

Sbragia, R., Andreassi, T.; Campanário, M. A.; Stal, E. (2005). Inovação: como vencer este desafio empresarial. São Paulo: Clio Editora. Zahar.

Schumpeter, Joseph. (1970). Teorias econômicas de Marx a Keynes. Rio de Janeiro:

Soares, Cleber O. (2012). Gado de Corte em retrato. Brasília-DF: Embrapa.

Tacla, Celso; Figueiredo, Paulo N. (2003). Processos de aprendizagem e acumulação de competências tecnológicas: evidências de uma empresa de bens de capital no Brasil. Revista de Administração Contemporânea, v. 7, n. 3, pp. 101-126.

Takeuchi, H; Nonaka, I. (2008) Gestão do conhecimento. Porto Alegre: Bookman.

Vieira Filho Eustáquio R. (2010). A Agricultura Brasileira: desempenho, desafios e perspectivas. Capítulo 3: Trajetória tecnológica e aprendizado no setor agropecuário. Brasília: IPEA. 